\title{
Fetal Macrosomia at the University Hospital Centre of Libreville: Epidemiological, Clinical, Risk Factors and Perinatal Prognosis
}

\author{
LEMBET MIKOLO Aude ${ }^{1,2}$, MINKO Julienne Isabelle ${ }^{1,2}$, MIMBILA Mylène ${ }^{2,3}$, MEKAME \\ MEYE Angela ${ }^{1,2}$, TCHANTCHOU Tanguy de Dieu ${ }^{3}$, MINTO'O Steeve ${ }^{1,2 *}$, ATEGBO Simon ${ }^{2,4}$, \\ KOKO Jean ${ }^{1,2}$ \\ ${ }^{1}$ University Hospital Center of Libreville-B.P. 2228-Libreville-Gabon \\ ${ }^{2}$ Departement of Pediatrics. Faculty of Medicine and Health Sciences-B.P. 4009-Owendo-Gabon \\ ${ }^{3}$ Omar Bongo Armies' Instructions Hospital - Libreville-Gabon \\ ${ }^{4}$ Jeanne Ebori Mother and Child University Hospital-Libreville-Gabon
}

*Corresponding Author: Dr Steeve MINTO’O, University Hospital Center of Libreville-B.P. 2228-LibrevilleGabon, E-mail: steeve.mintoo@yahoo.fr

\begin{abstract}
Objectives: To describe the epidemiological and clinical aspects of macrosomia, to evaluate the prognosis and to identify the risk factors of macrosomic newborns at the University Hospital Center of Libreville.
\end{abstract}

Patients and Methods: It was a case-control study, descriptive and analytical, from January $1^{\text {st }}$ to December 31, 2017in the birth room of the neonatal and neonatal resuscitation unit at the University Hospital Center of Libreville.

We compared new borns weighing at least 4000 grams to big fetus (weighing from 3500 to 3990 grams).

Results: The frequency of macrosomia was 3.8 5\%.Caesarean section was performed for macrosomia in $18.2 \%$ vs $25.3 \%$ in the control group $(p<0.001)$. Fetal complications were more frequent in the macrosomic neonates: $11.3 \%$ versus $0.4 \%(p=0.000)$. Neonatal mortality was estimated at $3.0 \%$. Factors associated with poor prognosis for macrosomic newborns were : Gestational age $>41$ weeks, birth weight $\geq 4500$ grams, male gender, vaginal delivery, and seated presentation.

Conclusion: Macrosomia is relatively common in our structure.The morbidity associated with multiple complications and early neonatal mortality is of concern.

\begin{abstract}
Abbreviations
CHUL: Centre Hospitalier Universitaire de Libreville - University Hospital Centre of Libreville, WHO: World Health Organization
\end{abstract}

Keywords: Macrosomia, Prevalence, Risk Factors, Prognosis, Libreville

\section{INTRODUCTION}

Fetal macrosomia is defined by a birth weight greater than 4000 grams [1, 2, 3, 4], on condition that this mass is about the whole body and not just one of its parts $[5,6]$.For other authors a newborn whose birth weight is above the $90^{\text {th }}$ percentile for gestational age is macrosomic [2, $7,8]$.

There is a worldwide trend to an increase of the frequency of high birth weight and fetal fetal macrosomia [8]. Fetal macrosomia was found in $1.6 \%$ and $28 \%$ of births, with a frequency varies according to countries $[4,9,10]$.In France, fetal macrosomia represents nearly $6.9 \%[8,11]$. In the USA it appears to be stabilizing from $8.5 \%$ in 1994 to $7.3 \%$ in 2003 [8]. In Africa, its frequency varies between $1.6 \%$ and $8.1 \%$ for the western and northern regions [ 5, 9, 12 15].In the Central region, there ported frequency is $4,1 \%, 5.7 \%$ and $7.8 \%$ respectively Congo Brazzaville, Gabon, Democratic Republic of Congo and Cameroon [2,4, 16,17].

The macrosomic newborn also called "colossus with feet of clay" is exposed to dystocia and consequences thereof. Fetal macrosomia is responsible of $10 \%$ indications of cesarean 
section, and 1 severe fetal injury per 1000 births $[19,20]$. In France, the delivery of big fetuses is dystocic in $39 \%$ of cases; with $15.1 \%$ of neonatal morbidity and $14.1 \%$ in mothers [ 20 , 21 ]. In primiparous women, fetal macrosomia is responsible of low fetal mortality rate and caesarian delivery with a rate of $26.0 \% \quad[20,21]$. In Tunisia, delivery of large fetus is responsible of $4.6 \%$ maternal morbidity, $3.6 \%$ among newborns and a fetal mortality of $12 / 1000$ [19]. The factors of poor fetal prognosis are fetal weight higher than 4500 grams, bad pregnancy follow-up, and complete dilatation upon arrival, prolonged labor length, prolonged delivery length, and instrumental extraction [19, 22].

The prognosis of the macrosomeis a constant concern for pediatric and gynecologists teams. In our context, it becomes a public health problem due to its consequences in terms of morbidity and mortality. In order to contribute to an amelioration of the macrosomic newborn care, this work aimed to determine the epidemiological and clinical factors of fetal macrosomia in our hospital, to assess the prognosis and to identify the occurrence of risk factors of complications in the macrosomic newborn and their mothers, comparing to a population of big fetuses.

\section{Material And Methods}

This was a prospective case-control study, descriptive and analytical, conducted between January $1^{\text {st }} 2017$ to December 312017 . It took place in the Neonatal Resuscitation and Neonatal Unit of the University Hospital Center of Libreville (CHUL). The study population consisted in all newborns at CHUL whose birth weight was greater than or equal to 3500 grams. They were divided into two groups: newborns whose birth weight was greater than or equal to 4000 grams (g) defined as macrosomic neonates, those whose birth weight was between 3500 and $3999 \mathrm{~g}$, defined as big neonates (big fetuses). For this control group, we selected one in four newborns that met the inclusion criteria. We did not included newborns whose birth weight greater than $4000 \mathrm{~g}$ but who had a congenital malformation such as: hydrocephalus, sacro-coccygeal tumors, or congenital cysts of the neck.

As the newborn was received in the birth room, we conducted a complete examination looking for malformations and obstetrical complications (brachial plexus lesions, femur fractures ) and was completed by administration of essential care and anthropometric measures as recommended by the World Health Organization (WHO). The measuring equipment consisted of a SECA $0155 \mathrm{D}{ }^{\circ}$ manual scale for weight gain (W in grams) and a non-expandable tape measure for the measurement of the length ( $\mathrm{L}$ in centimeters), the MUAC (in centimeters) and the head circumference $(\mathrm{HC}$ in $\mathrm{cm})$.

The data regarding mothers were recorded from the register of the delivery room.

The data were reported on collection form. The mothers variable were : the age (divided into four groups : $<20$ years, between 20-29 years, between 30-39 years, $\geq 40$ years), the level of education (primary, secondary, higher), the professional occupation, antecedents of fetal macrosomia and gestational diabetes, the gravidity (number of pregnancies), the parity (number delivery), the type of presentation (cephalic, siege, other ), the mode of delivery ( vaginal delivery, caesarean delivery) . Newborn variables were: the weight $(\mathrm{g})$ size $(\mathrm{cm})$, head circumference $(\mathrm{cm})$, sex, gestational age in weeks of amenorrhea, the Apgar score measured at the $1^{\text {st }}$ and $5^{\text {th }}$ minute of life, the evolution determined by survival or death. The post-term called extended term or term overrun was defined for a birth term greater than 41 weeks. The adaptation to external life was, three levels were retained: the state of apparent death for a score $\leq 3$ on 10 , morbid condition for a score between 4-6 on 10, and a normal adaptation for a value $\geq 7$ out of 10 .

The Schwartz formula was used to determine the minimum sample size. A sample of at least 61 neonates per group was needed.

Data was captured and analyzed using Microsoft Excel 2013 and SPSS 19.1 software. For continuous variables, we have calculated averages and extremes. As for the qualitative variables, the frequencies were calculated and were compared using the chi-test 2 . The means were compared by ANOVA test. A p value $\leq$ 0.05 was retained as significant.

\section{RESULTS AND DISCUSSION}

During the study period, 7845 births were registered, 302 newborns were macrosomic frequency of $3.85 \%$. The proportion of mothers under 30 years of age was lower among mothers of macrosomic newborns $(52.3 \%)$ than in mothers of big fetuses (71.7\%) .The mothers of macrosomic babies were older with a mean age of $29.3 \pm 6.1$ years compared to $26.8 \pm 6.0$ years 
for the mothers of the fetus newborns . The proportion of mothers aged 20 to 29 was about three times more likely to give birth to a big fetus than to a macrosomic newborn. The women in labor with level study secondary gave birth twice more to a macrosomic newborns that big fetuses $(66.6 \%$ versus $46.0 \%, p<0.02)$. Mothers having an activity were more likely to have a macrosomic newborn than big fetuses ( $29.1 \%$ versus $24,8 \%, p=N S)$. The antecedents of fetal macrosomia were significant in the mothers of macrosomic babies, compared to mothers of large fetuses (15.6\% vs $0.8 \%$, $p<0,001)$. The mothers who had gestational diabetes were three times more likely to have a macrosomic baby compared to mothers of big fetuses, but the relationships were not significant.
The parity and the mean gestitywere significantly higher among mothers of big fetuses than in mothers of macrosomic newborns respectively for parity $4.2 \pm 2.6$ versus $3.3 \pm 2.1$ and for gestity $3.5 \pm 2.2$ versus $2.2 \pm 1.4$ ( $\mathrm{p}<0.01)$. The proportion of mothers with low parity who had big fetuses was twice as high as in mothers of macrosomic babies, $44.0 \%$ versus $42,0 \%(\mathrm{p}<0.01)$. The proportion of multiparous mothers was higher in the macrosomic babies mothers than in mothers of big fetuses, $37.0 \%$ versus $15.0 \% \quad(p<0.01)$, while the primiparous mothers were more numerous when the newborn was a big fetus than macrosomic newborn, in respectively $41.0 \%$ and $21.0 \%$ of cases.

Table1. Distribution of macrosomic newborns and high birth weight fetuses according to socio demographic data, delivery and the maternal conditions related to childbirth

\begin{tabular}{|c|c|c|c|c|c|c|c|}
\hline \multirow{2}{*}{ Maternalcharacteristics } & \multicolumn{2}{|c|}{$\begin{array}{c}\begin{array}{c}\text { Macrosomic } \\
\text { newborn }\end{array} \\
\end{array}$} & \multicolumn{2}{|c|}{$\begin{array}{c}\text { High birth weight } \\
\text { fetus } \\
\end{array}$} & \multirow[b]{2}{*}{$p$} & \multirow[b]{2}{*}{ OR } & \multirow[b]{2}{*}{$95 \%$} \\
\hline & $\begin{array}{c}\mathrm{n} \\
\mathrm{N}=302\end{array}$ & $\%$ & $\begin{array}{c}\mathrm{n} \\
\mathrm{N}=237 \\
\end{array}$ & $\%$ & & & \\
\hline \multicolumn{8}{|l|}{ Age (years) } \\
\hline$<20$ & 9 & 3.0 & 27 & 11.4 & & & \\
\hline $20-29$ & 149 & 49.3 & 143 & 60.3 & 0.70 & 2.4 & 6.1 to 15.7 \\
\hline $30-39$ & 125 & 41.4 & 60 & 25.3 & & & \\
\hline$>40$ & 19 & 6.3 & 7 & 3.0 & & & \\
\hline \multicolumn{8}{|l|}{ Level of study } \\
\hline Primary & 40 & 13.2 & 93 & 39.2 & & & \\
\hline S econdaire & 201 & 66.6 & 109 & 46.0 & $<0.01$ & 2.3 & 1.6 to 3.3 \\
\hline Superior & 61 & 20.2 & 35 & 14.8 & & & \\
\hline \multicolumn{8}{|l|}{ Activityprofessional } \\
\hline Withoutactivity & 214 & 70.9 & 178 & 75.2 & & & \\
\hline Withactivity & 88 & 29.1 & 59 & 24.8 & 0,310 & 1.12 & 0.89 to 1.4 \\
\hline $\begin{array}{l}\text { Antecedents of fetal } \\
\text { macrosomia }\end{array}$ & 47 & 15.6 & 2 & 0.8 & $<0.01$ & 21.6 & 5.2 to 29.4 \\
\hline Gestational Diabetes & 2 & 0.7 & 1 & 0.4 & 0.710 & 3 & 3.7 to 12.5 \\
\hline \multicolumn{8}{|l|}{ Parity } \\
\hline primipare & 63 & 21.0 & 97 & 41.0 & & & \\
\hline fewpreviousdeliveries & 127 & 42.0 & 104 & 44.0 & $<0.01$ & 2.4 & 0.26 to 1.5 \\
\hline multiparous & 112 & 37.0 & 36 & 15.0 & & & \\
\hline \multicolumn{8}{|l|}{ Presentation } \\
\hline Cephalic & 297 & 98.3 & 230 & 97.0 & & & \\
\hline Seat & 11 & 1.7 & 7 & 3.0 & 0.55 & 2 & 0.2 to 18.4 \\
\hline \multicolumn{8}{|l|}{ Mode of delivery } \\
\hline vaginal & 247 & 81.8 & 177 & 74.7 & & & \\
\hline caesarean & 55 & 18.2 & 60 & 25.3 & $<0.01$ & 1.7 & 0.2 to 1.7 \\
\hline \multicolumn{8}{|l|}{ Maternalcomplications } \\
\hline $\begin{array}{l}\text { Presence } \\
\text { Absence }\end{array}$ & $\begin{array}{c}96 \\
206 \\
\end{array}$ & $\begin{array}{l}31.8 \\
68.2\end{array}$ & $\begin{array}{c}26 \\
211 \\
\end{array}$ & $\begin{array}{l}11.0 \\
89.0\end{array}$ & $<0.01$ & 2.9 & 4.1 to 22.4 \\
\hline
\end{tabular}

Infant's borned macrosomic were in cephalic presentation in $98.3 \%$, and $97.0 \%$ for big fetuses. The proportion of births in seat presentation was twice higher in big fetuses than in macrosomic newborns, although the difference is not significant. Caesarean delivery was performed in $25.3 \%$ of big fetuses, and in $18.2 \%$ for macrosomic $(p<0.01)$. Maternal complications linked to childbirth were 3 times 
more frequent in mothers of macrosomic babies than in mothers of big fetuses $(31.8 \%$ vs $11.0 \%$, $p<0.01)$. The main complications were perineal tear $(22.2 \%),(6.6 \%)$ and cervical tear $(2.0 \%)$. The distribution of macrosomic and large fetuses according to maternal characteristics, is indicated in Table 1.

The majority of post-term newborns were macrosomic newborns in $39.7 \%$, and in $15.6 \%$ bi fetuses, $p<0.01$. The male sex predominated in macrosomic with $66.6 \%$ compared to $57.4 \%$ in big fetuses, with a significant difference for a sex ratio of 1.99 against 1.35. Adaptation to extra uterine life in the first minute was poor for $10.6 \%$ of macrosomic, and in $15.2 \%$ for big fetuses, $p<0.01$. The apparent death state was found in $5.6 \%$ of the macrosomic and in none of the big fetuses. At the fifth minute, adaptation to extra uterine life remained poor for $1.7 \%$ of macrosomic versus $3.8 \%$ big fetuses. The apparent state of death was found in $2.6 \%$ of macrosomic newborns after resuscitation. The absence of complications was reported twice in big fetuses as in macrosomic neonates: $99.6 \%$ versus $88.7 \%$ with a significant difference. Complications were observed among macrosomic newborns in $11.3 \%$ of cases versus $0.4 \%$ for big fetuses. They were lead by brachial plexus $(7.3 \%)$, followed by the read attachment shoulder $(0.7 \%)$, clavicle fracture $(0.3 \%)$. Death occurred in $3.0 \%$ of cases (9/302) among newborns and none in big fetus. Table 2 gives the distribution of neonates macrosomic babies and big fetuses according to neonatal characteristics.

Table2.Distribution of macrosomic newborns and fetuses big s e scording term birth sex, Apgar score the $1^{\text {st }}$ to the $5^{\text {th }}$ minute of life and the existence of fetal complications

\begin{tabular}{|l|c|c|c|c|c|c|c|}
\hline Neonates characteristics & \multicolumn{2}{|c|}{ Macrosomic new borns } & \multicolumn{2}{c|}{ Big fetuses } & p & OR & 95\% \\
\hline & $\begin{array}{c}\mathrm{n} \\
\mathrm{N}=302\end{array}$ & $\%$ & $\begin{array}{c}\mathrm{n} \\
\mathrm{N}=237\end{array}$ & $\%$ & & & \\
\hline Birth term & & & & & & & \\
\hline A term & 182 & 60.2 & 200 & 84.4 & & & \\
\hline In post-term & 120 & 39.7 & 37 & 15.6 & $<0.01$ & 1.2 & 0.6 to 4.2 \\
\hline Sex & & & & & & & \\
\hline Male & 201 & 66.6 & 136 & 57.4 & $<0.01$ & 1.1 & 0.5 to 6.2 \\
\hline Female & 101 & 33.4 & 101 & 42.6 & & & \\
\hline Apgar at 1 mn & & & & & & & \\
\hline$\leq 3$ & 17 & 5.6 & 0 & 0 & & & \\
\hline $4-6$ & 32 & 10.6 & 36 & 15.2 & 0.02 & 1.5 & 0.7 to 2.9 \\
\hline$\geq 7$ & 253 & 83.8 & 201 & 84.8 & & & \\
\hline Apgar at 5mn & & & & & & & \\
\hline$\leq 3$ & 8 & 2.6 & 0 & 0 & & & \\
\hline $4-6$ & 5 & 1.7 & 9 & 3.8 & 0.01 & 1.14 & 0.48 to 3.1 \\
\hline$\geq 7$ & 289 & 95.7 & 228 & 96.2 & & & \\
\hline Fetal complications & & & & & & & \\
\hline Presence & 34 & 11.3 & 1 & 0.4 & & & \\
\hline Absence & 268 & 88.7 & 236 & 99.6 & $<0.01$ & 1.89 & 0.85 to 1.93 \\
\hline
\end{tabular}

The prevalence of macrosomic babies in this study is similar to that found by Iloki in Congo Brazzaville at $4.0 \%$ [16], and NgouMvéNgou in Libreville Gabon with $4.1 \%$ [17] . It is higher to that found in studies of Badji et al in Senegal with $1.57 \%$ [9], de Thieba et al in Burkina Faso with $2.1 \%$ [22]. This prevalence rate lower than that reported by Sanogoin Maliwith5.02\%[5], by Fettahin Morocco with 5.64\%[13],by Kakudjiet alin the Democratic Republic of Congo with $5.7 \%$ [2]. Higher frequencies have been reported by Ananthin Canada and the United States [23] with $24 \%$.

The incidence of fetal macrosomia varies by region and depends on racial, ethnical and local differences [24]. According to Cheng, the difference in weight distribution at birth is due to genetic differences and anthropometric abnormalities between populations [25]. The low prevalence reported in African studies may be explained by the monocentric design, as well as malnutrition, inadequate monitoring, lack of hygiene during pregnancy and low socioeconomic level. The notion that mothers of macrosomic babies are older than neonates of normal birth weight or large fetuses has been confirmed by other authors. Kakudji et al in the Democratic Republic of Congo finds an average of maternal age of $30,0 \pm 6.0$ years against $28.3 \pm 6.3$ years among mothers of newborns of 
normal weight [2 ], Usta et al in Turkey reported a mean maternal age of $28.0 \pm 5.9$ years significantly higher in the group of newborns macrosomics than among mothers of normal newbornswith $26.8 \pm 5.7$ years $(\mathrm{p}=0.0003)$ [3] Iloki et al in the Republic of Congo found a mean age of mothers of $27.7 \pm 6.2$ years versus $26.5 \pm 5.5$ years for control cases $(\mathrm{p}=0.0021)$ [1]. Akin et al Turkey reports a mean maternal age of $28.3 \pm 5,6$ years in the population of mothers of macrosomic babies and 26,7 $\pm 5,28$ years in that of normal neonates $(p=0,0001)$ and in Iran Kargar et al reports a significant difference in the average maternal age between the case group (29.6 \pm 6.1 years) and control group $(27.9 \pm 8.3$ years $)(p<0.001)[26,27]$.

Correlation between a multiparity, multigestity and the birth of a newborn macrosome has been noted by other authors, such as Kakudji et al in the Democratic Republic of Congo [2 ], Roger et al in Cameroon [4], Ezegwui in Nigeria [12] , Iloki in the Republic of Congo [16] , NgouMvéNgouet al in Gabon [17], Kargar et al in Iran [ 27] . Multi parity is a risk factor because it is associated with high maternal age and consequently the progressive dystocia.

Antecedents of birth of a macrosomic newborn is a factor and intervals siness associated with the occurrence of a macrosomic. Ezegwuiet al in Nigeria found that mothers with an antecedent of macrosomic newborns were more prevalent at $35.5 \%$ compared to $12.5 \%$ of mothers of normal neonates [12]. NgouMvéNgouin Gabon reports $14.6 \%$ of antecedent of fetal macrosomia in maternal history and Touhami et al in Morocco $4 \%$ [17, 28].These studies also confirmed that diabetes and obesity are risk factors for the birth of macrosomic newborns. The low rate found in our work can be explained by absence of hyperglycemia during pregnancy for most parturients.

Vaginal delivery were more frequent in mothers of macrosomic newborns compared to mothers of big fetuses is reported by several authors , such as Kakudji et al in Democratic Republic of Congo, Sanogo et al in Mali and NgouMvéNgou et al in Gabon, who find respectively $84.4 \%$ [2 ], $80 \%$ [ 5] and $60.8 \%$ [17]. The proportion of cesarean delivery was higher in mothers of big fetuses in our study may be explained by its indication easily placed among first-time mothers because of the higher risk of obstructed labor.
The higher proportion of post-term neonates in macrosomic babies confirms the correlation between gestational age and fetal macrosomia observed in other series. Those of Keita et al in Mali [ 6], Badji et al in Senegal [9] and Buisson et al in France [ 20 ].Fetal macrosomia e would promote the prolongation of the term through the fœto- pelvic disproportion.

The predominance of male in macrosomic babies compared to the newborn's large fetus is also reported by Kakudji et al in the Democratic Republic of Congo with $61.7 \%$ versus $48.9 \%$ for the control group [2 ],Nzalli Tango et al in Cameroon with $60.3 \%$ versus $40.5 \%$ for controls ( $p<0.001)$ [4], Touhami et al in Morocco with $67 \%$ of cases [28]. All authors agree that male newborns have a higher weight than females at any gestational age, without any arguments being advanced.

The proportion of maternal complications found in mothers macrosomic babies were more important than those of large big fetuses, and was greater than the reported result by NgouMvéNgou et al in Gabon with 10.8\%[17].Nzalli Tango et al in Cameroon, reports that maternal morbidity was more important in fetal macrosomia $(20.7 \%$ versus $11.2 \% ; p=0.005)$. This result can be explained by the failure monitoring of big fetuses with the corollary no screening of pelvic disproportions.

Frequency of complications in neonates were associated with shoulder dystocia in macrosomic babies compared to conytrol was comparable to that found by NgouMvéNgou et al in Gabon with 8.9\% [17].Boulanger in France reported a higher prevalence of $30.3 \%$ [29]. Batallan et al in France observed 10 times more shoulder dystocia in mothers of newborns macrosomic babies than in non-macro some neonates [11]. These results suggest that birth trauma can be prevented by opting for cesarean section. The rate of perinatal asphyxia in newborns was macrosomic less than that found e by Keita and Sanogo in Mali with respectively $17 \%$ [6] and $8.6 \%$ [5].We did not find a prevalence more important compared to big fetuses; while mortality was associated with fetal macrosomia as reported by Said et al [14]. Kakudjiet al in Lubumbashi in Congo Democratic Republic describes the case of perinatal complications, although the group macrosomic $t$ have clinically recorded high proportions of fetal death in utero, neonatal 
depression (Apgar score at the $5^{\text {th }}$ minute $<7$ ), traumatic lesions and cord circular, the analysis did not show a statistically significant difference compared to the control group ( $p>0.05$ ) [2 ]. Batallanet al in France in a multicentre survey concluded that the fetal macrosomia was not associated with excess neonatal morbidity (trauma, Apgar score, cord $\mathrm{pH}$, neonatal transfer) [11].The neonatal morbidity seems to be linked to support delay of deliveries in case of pelvic disproportion, including the turnaround time of caesarean section when complications are identified. The risk factors for occurrence of complications in newborns macrosomic babies are comparable with data from the literature which show that neonatal morbidity increases with birth weight [11]. Variations in the series can be attributed to differences in management of pregnancies at risk, in particular the choice of mode of delivery which must take into account maternal and neonatal risks related to the vaginal way.

\section{CONCLUSION}

The prevalence of macrosomia is high in our context. Maternal factors were the secondary level of education, antecedents of fetal macrosomia and multi parity. Neonatal factors were the post-term, male sex, vaginal delivery remains a source of perinatal complications.

Support in the birth room should be multidisciplinary and goes on by improving a good quality of obstetric and neonatal care involving gynecologists-obstetricians and pediatricians- neonatologists. The reduction of complications involves the screening and monitoring of high-risk pregnancies, improving the technical context in delivery room as well strengthening the skills of caregivers in neonatal resuscitation.

\section{REFERENCES}

[1] SL Ball, Alexander GR, Salihu HM et al .Macrosomic births in the United States: determinants, outcomes and proposed grades of risk. Am J Obstet Gynecol.2003: 188 (5): 1372 8.

[2] KakudjiLuheteP ,Mukuku O, MubindaKiopin P et al . Fetal fetal macrosomia in Lubumbashi: risk factors and maternal and perinatal prognosis. Pan Afr Med J.2016 23: 166 doi: 10. 11604 /pamj.2016.23.166.7362 .

[3] Usta A, SancakliUsta C, Yildiz A et al. Frequency of fetal fetal macrosomia and the risk factors in pregnancies without gestational diabetes mellitus . Pan Afr Med J. 2017 26:62 doi : 10.11604 / pamj.2017.26.62.11440
[4] Nzalli Tango GR .Fetal fetalmacrosomia : To become maternal and neonatal early at the Yaoundé University Hospital Center and Central Hospital of Yaoundé and the HCY. The journal $\mathrm{J}$ of Med Sc iences ECINE and health. 2013 ; http://www.hsdfmsb.borg/index.php/ hsd /thesis/view/97

[5] SanogoAC .Epidemiological and clinical study of fetal fetal macrosomia at the reference health center of commune II. Thesis Med. Bamako, 2009, No. 119 : 93 p.

[6] A K eita. Epidemiologic -clinical study of fetal fetal macrosomia observed in the reference health center of commune IV concerning 100 cases. Thesis Med. Bamako, 2006; No. 232: 72 p.

[7] Carlus C, P acault A, by Gamarra E et al .The newborn macrosome in maternity. J Gynecol Obstet Biol Reprod .2000;29 (1) :25-32.

[8] Mazouni C JP Menard, Gamerre M, L Cravello. Will the fetus macrosome become an obese adult?.The Gynecologist'sLetter.2009； 341-34 2 :29-31.

[9] Badji CA, Moreau JC, Ba MG et al .The delivery of the big child to the Dakar chu: epidemiology and prognosis. Med Afr Black. 1999;46: 355-8 .

[10] Jensen DM, Damm P, Sorensen B et al. Clinical impact of mild carbohydrate intolerance in pregnancy: a study of 2904 nondiabetic. Am J ObstetGynecol. 2001;185: 413-9 .

[11] BatallanA,GoffinetF,LladoJP et al.Fetal macrosomia: practices, obstetric and neonatal consequences.Multicentre case-control survey conducted in 15 maternity hospitals in Paris and Île de France. Gynecology Obstetrics \& Fertility.2002;30 (6): 483-491

[12] EzegwuiHU, IkeakoLC, EgbujiC.Fetal fetal macrosomia Obstetric outcome of 311 cases in UNTH, Enugu, Nigeria. Niger J ClinPract. 2011; 14 (3): 322-6.

[13] Fattah million. Fetal fetal macrosomia at term (about 340 cases). Thesis Med. Morocco, 2016; No. 165/16: $125 \mathrm{p}$.

[14] Said AS, Premji Manji K.Risk factors and outcomes of fetal fetal macrosomia in a tertiarycenterin Tanzania: a case-control study . BMC Pregnancy Childbirth. 201616 (1): 243 .

[15] AlkahatimAlsammani M, Roshdy Ahmed S. Fetal and Maternal Outcomes in Pregnancies Complicated with Fetal Fetal macrosomia. N Am J Med Sci. 2012; 4 (6): 283-6.

[16] Iloki LH, Itoua C, Mbemba Mutounou GM, Massouama $\mathrm{R}$ et al. Fetal fetalmacrosomia: risk factors and maternal- fetal complications in 
Brazzaville (Republic of Congo). Med Afr Black. 2014; 61 (10): 479-486.

[17] NgouMvéNgou JP, Mouba JF, Mimbila M et al .The newborn macrosomic motherhood of Jeanne Fondati we Ebori: about 212 cases. Bull Med Owendo 2008;12 (32): 78-81.

[18] De Meus JB, Deshayes M, Magnin G. Dystocia by excess of fetal volume. Encycl Med Chir Paris Obstetrics1991;5067A10: 11.

[19] Ouarda C, Ma rzouk A, Ben Youssef L et al .The neonatal and maternal prognosis of the birth of a single, long- term fetus : about 497 cases. J GynecolObstet Biol Reprod 1989, 18: 360-6.

[20] Bush MP, Quereu C, Palot M et al .Birth of the big child. About 222 observations. J GynecolOb Stet Biol Reprod .1991;20: 871-2

[21] Panel P Meeus JB Yanoulopoulos B. Delivery of large fetus. J GynecolObstet Biol Reprod1990;19: 729-736.

[22] Thieba B, Akontionga M, Ouedraogo A et al. Large fetus: maternal -fœtal prognosis about 143 cases in the maternity of the university hospital in Ouagadougou. Journal of SAGO. 2004;5: 22-8.

[23] Ananth CV, Wen SW. Trends in fetal growth among singleton gestations in the United States and Canada, 1985 through 1998. SeminPerinatol. 2002;26 (4):260-7.

[24] Henriksen T. The macrosomic fetus: A challenge in current obstetrics. Acta Obstet GynecolScand. 2008;87 (2): 134-45.

[25] Cheng YK, Lao T,Sahota DS, Leung VK et al. Use of birth weight threshold for fetal macrosomia to identify fetuses at risk of shoulder dystocia among Chinese populations. Int J Gynecol Obstet. 2013; 120 (3): 249-53.

[26] Akin Y, Cömert S, TuranC,Píçak A et al. Macrosomic newborns:a 3-year review. Turk J Pediatr .2010;52 (4): 378-83.

[27] Kargar Maher MH, S. S oltani,Zeinalzadeh AH et al. Complications and Risk Factors of Neonatal Fetal macrosomia: A Case Study Control. Iranian Journal of Neonatology. 2018; 9 (1).doi: 10.22038/ijn.2018.23827.1304.

[28] ThamiElouazzani F, Kabiri M, KarboubiL et al .Fetalmacrosomia: about 255 cases. Journal of Pediatrics and Childcare. 2012;25 (2): 97-101.

[29] Baker L, Mubiayi N, Goueff F et al. Fetal macrosomia: experience of maternity Paul Gelle . J GynecolObstet Biol Reprod .2003; 32 (7): 8-9.

Citation: LEMBET MIKOLO Aude et al. Fetal Macrosomia at the University Hospital Centre of Libreville: Epidemiological, Clinical, Risk Factors and Perinatal Prognosis. ARC Journal of Pediatrics.2019; 5(1):2-8. doi:dx.doi.org/10.20431/2455-5711.0501002.

Copyright: (C) 2019 Authors. This is an open-access article distributed under the terms of the Creative Commons Attribution License, which permits unrestricted use, distribution, and reproduction in any medium, provided the original author and source are credited. 